\title{
Heat Capacities of Polyethylene IV. High Molecular Weight Linear Polyethylene
}

\author{
Shu-Sing Chang \\ Institute for Materials Research, National Bureau of Standards, Washington, D.C. 20234
}

(August 27, 1975)

\begin{abstract}
A high molecular weight linear polyethylene sample has been studied by adiabatic calorimetry from 10 to $380 \mathrm{~K}$. Two broad temperature regions of unusual spontaneous temperature drift have been observed. The phenomena occurring around $240 \mathrm{~K}$ are similar to that observed in other polyethylene samples studied in this series, and are presumed to be caused by the relaxational processes in the amorphous phase. The weak exothermic behavior occurring around $160 \mathrm{~K}$ is presumed to be caused by the stabilization of the quenched sample.
\end{abstract}

Key words: Glass transition; heat capacity; high molecular weight linear polyethylene; polyethylene; temperature drift; thermodynamic properties.

\section{Introduction}

The heat capacity behavior of a sample of high molecular weight linear polyethylene has been studied recently by Beatty and Karasz [1, 2]. ${ }^{1}$ High molecular weight polyethylene is more difficult to crystallize than lower molecular weight polyethylene. Increased amorphous content should provide a stronger indication of the existence of a glass transition in partially crystalline linear polyethylene. A region of rather abrupt change in the heat capacity differences between that high molecular weight sample and a linear polyethylene sample studied by Dainton et al. [3] was noted. For the quenched high molecular weight sample, there was an 8 percent increase in the heat capacity occurring in the temperature region 130 to $190 \mathrm{~K}$. For the annealed sample, there was about 5 percent increase. At higher temperatures a bend in the heat capacity curve was noted similar to Dainton's data. The region near $150 \mathrm{~K}$ was assigned as the glass transition temperature of linear polyethylene. Spontaneous temperature drifts under adiabatic conditions, indicative of relaxational processes, were not noted in detail.

A similar high molecular weight linear polyethylene sample from the same manufacturer was studied in this laboratory in the temperature range from 10 to $380 \mathrm{~K}$. Detailed spontaneous temperature drifts were carefully observed on the sample under various thermal treatments. The results and conclusions from this

'Figures in brackets indicate the literature references at the end of this paper. study are somewhat different from the previously mentioned literature.

\section{Experimental Section}

\subsection{Calorimetry}

Heat capacity measurements on the high molecular weight linear polyethylene sample were made with the same vacuum adiabatic calorimeter [4] that was used in the previous studies $[5,6]$ on polyethylene samples derived from Standard Reference Materials 1475 and 1476.

\subsection{Materials}

A sample of high molecular weight polyethylene was furnished by Dr. R. J. Schaffhauser of the Plastics Division, Allied Chemical Corp.,${ }^{2}$ bearing the designation 260-100. This resin was at one time also designated as AC8X, as was Beatty's sample [2]. It was produced by Ziegler-type vapor phase polymerization. Its molecular weight is estimated by the manufacturer as $8-13 \times 10^{6}$. It has an ash content of 0.04 percent and contains no additives. The molecular weights are estimated in the order of $2.7-3 \times 10^{6}$ by both viscometry and light scattering measurements from the Polymer Characterization Section of the National Bureau of Standards. Whether the discrepancy in the molecular weights is caused by the degradation of the polymer

\footnotetext{
${ }^{2}$ Commercial materials are identified in this paper to adequately specify the experimenta procedure. Such identification does not imply recommendation or endorsement by the National Bureau of Standards.
} 


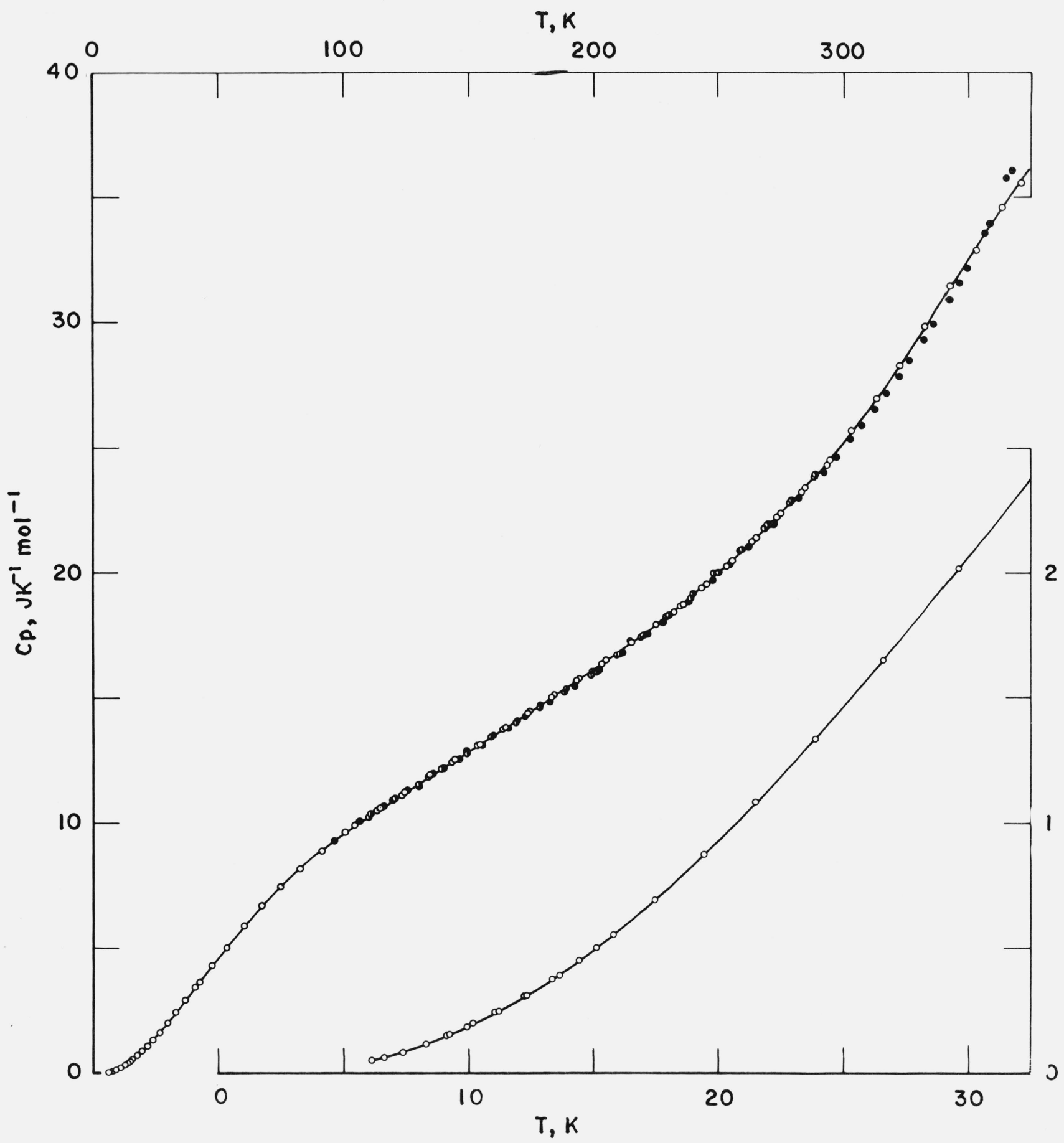

FIGURE 1. Heat capacity of high molecular weight linear polyethylene.

Annealed at $<300 \mathrm{~K}$,

at high temperatures or by differences in the procedures to estimate the molecular weight was not determined.

The sample was received in the form of a powder. Attempts to fuse the powder together under its own weight in vacuum at $150{ }^{\circ} \mathrm{C}$ were not successful due to the high viscosity of the melt. The heating produced a sintered product. In order to avoid degradation of the high molecular weight material at high pressure and temperature, molding was not tried.

The material was pressed into pellets of about 1.27 $\mathrm{cm}$ in diameter and about $1 \mathrm{~cm}$ in height in a hydraulic press at room temperature. $73.891 \mathrm{~g}$ (mass in vacuum) of the material was loaded in the sample container for 
at $3.8 \mathrm{~cm} \mathrm{Hg}(5.1 \mathrm{kPa})$ at room temperature was sealed in to improve thermal conduction within the sample container.

\section{Results}

The results of the heat capacity measurements are tabulated in table 1 and shown graphically in figure 1. Table 1 is separated into various sections according to the thermal treatment the sample received. Within the section, the data are arranged in the order of increasing initial temperature of a series of heat capacity measurements. The series are numbered in chronological sequence throughout table 1 in order to facilitate the tracing of the thermal history of the sample.

TABLE 1. Heat capacity data of high molecular weight linear polyethylene

\begin{tabular}{|c|c|c|c|}
\hline$T, K$ & $C_{p}, \mathrm{~J} \mathrm{~K}^{-1} \mathrm{~mol}^{-1}$ & $T, K$ & $C_{p}, \mathrm{~J} \mathrm{~K}^{-1} \mathrm{~mol}^{-1}$ \\
\hline \multicolumn{4}{|c|}{ Quenched } \\
\hline \multicolumn{2}{|c|}{ SERIES X } & \multicolumn{2}{|c|}{ SERIES III } \\
\hline 6.13 & 0.0507 & 104.82 & 9.895 \\
\hline 6.62 & .0623 & 114.82 & 10.59 \\
\hline 7.38 & .0843 & 124.63 & 11.24 \\
\hline 8.33 & .1170 & 134.58 & 11.88 \\
\hline 9.26 & .1558 & 144.57 & 12.51 \\
\hline 10.18 & .1982 & 154.63 & 13.16 \\
\hline 11.18 & .2484 & 164.68 & 13.81 \\
\hline 12.33 & .3130 & 174.62 & 14.46 \\
\hline 13.64 & .3954 & 184.56 & 15.11 \\
\hline 15.13 & .5016 & 194.64 & 15.78 \\
\hline \multicolumn{2}{|c|}{ SERIES IX } & \multicolumn{2}{|c|}{ SERIES VIII } \\
\hline 9.11 & 0.1500 & 113.50 & 10.50 \\
\hline 9.96 & .1875 & 123.38 & 11.16 \\
\hline 11.06 & .2445 & 133.50 & 11.81 \\
\hline 12.27 & .3106 & 143.76 & 12.46 \\
\hline 13.37 & .3773 & 153.86 & 13.11 \\
\hline 14.48 & .4536 & 163.71 & 13.74 \\
\hline 15.80 & .5549 & 173.57 & 14.39 \\
\hline 17.50 & .6963 & 183.45 & 15.06 \\
\hline 19.45 & .8758 & 193.35 & 15.69 \\
\hline 21.51 & 1.082 & 203.39 & 16.36 \\
\hline 23.87 & 1.335 & & \\
\hline 26.59 & 1.649 & & \\
\hline 29.63 & 2.015 & & \\
\hline 32.96 & 2.437 & & \\
\hline 36.62 & 2.916 & & \\
\hline 40.68 & 3.453 & & \\
\hline \multicolumn{2}{|c|}{ SERIES XI } & \multicolumn{2}{|c|}{ SERIES IV } \\
\hline 42.32 & 3.663 & 205.32 & 16.51 \\
\hline 47.20 & 4.296 & 215.33 & 17.21 \\
\hline 53.44 & 5.085 & 225.29 & 17.92 \\
\hline 60.36 & 5.906 & 235.29 & 18.69 \\
\hline 67.54 & 6.690 & 245.31 & 19.55 \\
\hline 74.97 & 7.436 & 255.21 & 20.44 \\
\hline 82.91 & 8.171 & 265.11 & 21.38 \\
\hline 91.40 & 8.882 & 274.99 & 22.37 \\
\hline \multirow[t]{2}{*}{100.88} & 9.609 & 284.83 & 23.41 \\
\hline & & 294.73 & 24.55 \\
\hline
\end{tabular}

TABLE 1. Heat capacity data of high molecular weight linear polyethylene-continued

\begin{tabular}{cc||cc}
\hline \hline$T, K$ & \multicolumn{1}{c||}{$C_{p}, \mathrm{~J} \mathrm{~K}^{-1} \mathrm{~mol}^{-1}$} & $T, K$ & $C_{p}, \mathrm{~J} \mathrm{~K}^{-1} \mathrm{~mol}^{-1}$ \\
\hline \multicolumn{3}{c}{ Quenched } \\
\hline \multicolumn{3}{c}{ SERIES V } \\
\hline \multicolumn{3}{c}{ SERIES XII } \\
205.41 & 16.50 & 303.29 & 25.70 \\
215.44 & 17.19 & 313.08 & 26.96 \\
225.40 & 17.92 & 322.98 & 28.27 \\
232.41 & 18.45 & 332.98 & 29.80 \\
236.45 & 18.77 & 342.96 & 31.43 \\
243.46 & 19.40 & 353.02 & 32.84 \\
253.42 & 20.29 & 363.28 & 34.56 \\
263.36 & 21.23 & 370.79 & 35.52 \\
273.38 & 22.21 & & \\
283.37 & 23.26 & & \\
293.33 & 24.35 & & \\
\hline
\end{tabular}

Slow-Cooled from $295 \mathrm{~K}$

\begin{tabular}{ll||ll}
\hline \multicolumn{2}{c}{ SERIES I } & \multicolumn{2}{c}{ SERIES II } \\
\hline 111.21 & 10.35 & 201.20 & 16.06 \\
120.85 & 10.98 & 210.86 & 16.75 \\
130.04 & 11.57 & 220.65 & 17.49 \\
139.42 & 12.16 & 230.44 & 18.30 \\
149.33 & 12.79 & 240.24 & 19.14 \\
159.23 & 13.41 & 250.03 & 20.02 \\
169.02 & 14.02 & 259.82 & 20.95 \\
178.84 & 14.64 & 269.70 & 21.92 \\
188.70 & 15.26 & 279.57 & 22.92 \\
198.69 & 15.91 & 289.33 & 23.96 \\
\hline
\end{tabular}

Quenched and then annealed at $225 \mathrm{~K}$, and $143 \mathrm{~K}$

\begin{tabular}{|c|c|c|c|}
\hline \multicolumn{2}{|c|}{ SERIES VI } & \multicolumn{2}{|c|}{ SERIES VII } \\
\hline 110.07 & 10.27 & 209.60 & 16.67 \\
\hline 120.01 & 10.94 & 219.52 & 17.42 \\
\hline 129.92 & 11.57 & 229.35 & 18.23 \\
\hline 139.87 & 12.20 & 239.08 & 19.10 \\
\hline 149.65 & 12.83 & 248.78 & 20.03 \\
\hline 159.42 & 13.44 & 258.62 & 20.84 \\
\hline 169.42 & 14.07 & 268.58 & 21.76 \\
\hline 179.44 & 14.70 & 278.62 & 22.76 \\
\hline 189.48 & 15.34 & 288.71 & 23.84 \\
\hline 199.55 & 16.00 & & \\
\hline \multicolumn{4}{|c|}{ Annealed at $370 \mathrm{~K}$} \\
\hline \multicolumn{2}{|c|}{ SERIES XIII } & \multicolumn{2}{|c|}{ SERIES XIV } \\
\hline 283.27 & 23.10 & 340.49 & 30.54 \\
\hline 292.99 & 24.16 & 349.78 & 32.17 \\
\hline 302.85 & 25.33 & 358.71 & 33.95 \\
\hline 312.75 & 26.54 & 367.28 & 36.05 \\
\hline 322.67 & 27.87 & & \\
\hline 332.59 & 29.29 & & \\
\hline 342.49 & 30.88 & & \\
\hline \multicolumn{4}{|c|}{ Slow-Cooled from $370 \mathrm{~K}$} \\
\hline \multicolumn{2}{|c|}{ SERIES XV } & \multicolumn{2}{|c|}{ SERIES XVII } \\
\hline 96.80 & 9.29 & 228.40 & 18.00 \\
\hline 106.83 & 10.03 & 238.11 & 18.84 \\
\hline 116.47 & 10.69 & 247.90 & 19.72 \\
\hline 126.09 & 11.31 & 254.90 & 20.29 \\
\hline 135.86 & 11.96 & 262.09 & 21.01 \\
\hline 145.80 & 12.55 & 272.14 & 21.97 \\
\hline 155.72 & 13.17 & 282.08 & 22.99 \\
\hline 165.63 & 13.79 & 292.09 & 24.05 \\
\hline
\end{tabular}


TABLE 1. Heat capacity data of high molecular weight linear polyethylene-continued

\begin{tabular}{cc||cc}
\hline \hline$T, K$ & $C_{p}, \mathrm{~J} \mathrm{~K}^{-1} \mathrm{~mol}^{-1}$ & $T, K$ & $C_{p}, \mathrm{~J} \mathrm{~K}^{-1} \mathrm{~mol}^{-1}$ \\
\hline \multicolumn{4}{c}{ Slow-Cooled from $370 \mathrm{~K}$} \\
\hline \multicolumn{3}{c}{ SERIES XVI } & \multicolumn{2}{c}{ SERIES XVIII } \\
\hline 172.39 & 14.21 & 297.52 & 24.63 \\
182.23 & 14.83 & 307.32 & 25.90 \\
192.21 & 15.45 & 317.06 & 27.14 \\
202.23 & 16.10 & 326.91 & 28.46 \\
212.18 & 16.79 & 336.84 & 29.93 \\
222.06 & 17.52 & 346.75 & 31.57 \\
& & 356.51 & 33.45 \\
& & 366.15 & 35.72 \\
\hline
\end{tabular}

Quenched samples were produced by admitting helium gas to the cryostat while the assembly was submerged in liquid nitrogen. A cooling rate in the order of 4-5 K $\mathrm{min}^{-1}$ was achieved. Slow-cooling (rate annealing) rates of $0.5-1 \mathrm{~K} \mathrm{~h}^{-1}$ were often used in conjunction with isothermal annealing (soak annealing) at a particular temperature for a period of days.

The temperature increment for a heat capacity determination may be inferred from the differences in the mean temperatures of the adjacent determinations within the series. Curvature corrections have been added to correct for the effect of the finite temperature increment of a determination. The precision of the measurement above $25 \mathrm{~K}$ is in the order of 0.05 percent. Below $25 \mathrm{~K}$, the precision gradually changes to about 1 percent at $5 \mathrm{~K}$. The accuracy over most of the temperature range of the measurement is comparable to the precision as indicated by heat capacity measurements on a Calorimetry Conference standard sample of sapphire [4].

Smoothed heat capacity values representing those of a quenched $\left(5 \mathrm{~K} \mathrm{~min}^{-1}\right)$ high molecular weight linear polyethylene are listed in table 2. Enthalpy and entropy increments referring to the zero point enthalpy and the residual entropy of the sample are also listed. Since the partially crystalline sample is expected to have undetermined residual entropies at $0 \mathrm{~K}$, Gibbs free energy is not given in table 2.

TABLE 2. Thermodynamic properties of high molecular weight Linear Polyethylene

$$
\left(-\mathrm{CH}_{2}-=14.027\right)
$$

\begin{tabular}{cccc}
\hline \hline$T, K$ & $C_{p}, \mathrm{~J} \mathrm{~K}^{-1} \mathrm{~mol}^{-1}$ & $\mathrm{H}-\mathrm{H}_{0}, \mathrm{~J} \mathrm{~mol}^{-1}$ & $\mathrm{~S}-\mathrm{S}_{0}, \mathrm{~J} \mathrm{~K}^{-1} \mathrm{~mol}^{-1}$ \\
\hline 5 & 0.037 & 0.047 & 0.012 \\
10 & .190 & .527 & .073 \\
15 & .492 & 2.175 & .203 \\
0 & .929 & 5.677 & .401 \\
25 & 1.463 & 11.63 & .664 \\
30 & 2.062 & 20.41 & .983 \\
35 & 2.702 & 32.31 & 1.349 \\
40 & 3.360 & 47.47 & 1.752 \\
45 & 4.016 & 65.91 & 2.186 \\
50 & 4.656 & 87.60 & 2.642 \\
60 & 5.862 & 140.3 & 3.600 \\
70 & 6.946 & 204.4 & 4.586
\end{tabular}

TABLE 2. Thermodynamic properties of high molecular weight Linear Polyethylene-continued $\left(-\mathrm{CH}_{2}-=14.027\right)$

\begin{tabular}{|c|c|c|c|}
\hline$T, K$ & $C_{p}, \mathrm{~J} \mathrm{~K}^{-1} \mathrm{~mol}^{-1}$ & $\mathrm{H}-\mathrm{H}_{0}, \mathrm{~J} \mathrm{~mol}^{-1}$ & $\mathrm{~S}-\mathrm{S}_{0}, \mathrm{~J} \mathrm{~K}^{-1} \mathrm{~mol}^{-1}$ \\
\hline 80 & 7.909 & 278.8 & 5.578 \\
\hline 90 & 8.769 & 362.3 & 6.560 \\
\hline 100 & 9.545 & 453.9 & 7.525 \\
\hline 110 & 10.26 & 553.0 & 8.469 \\
\hline 120 & 10.94 & 659.0 & 9.391 \\
\hline 130 & 11.59 & 771.7 & 10.29 \\
\hline 140 & 12.22 & 890.7 & 11.17 \\
\hline 150 & 12.86 & 1016. & 12.04 \\
\hline 160 & 13.50 & 1148. & 12.89 \\
\hline 170 & 14.15 & 1286. & 13.73 \\
\hline 180 & 14.81 & 1431. & 14.55 \\
\hline 190 & 15.47 & 1582. & 15.37 \\
\hline 200 & 16.14 & 1740. & 16.18 \\
\hline 210 & 16.82 & 1905. & 16.99 \\
\hline 220 & 17.52 & 2077. & 17.79 \\
\hline 230 & 18.27 & 2256. & 18.58 \\
\hline 240 & 19.09 & 2443. & 19.38 \\
\hline 250 & 19.96 & 2638. & 20.17 \\
\hline 260 & 20.90 & 2842 . & 20.97 \\
\hline 270 & 21.87 & 3056. & 21.78 \\
\hline 280 & 22.89 & 3280. & 22.59 \\
\hline 290 & 24.00 & 3514. & 23.42 \\
\hline 300 & 25.20 & 3760. & 24.25 \\
\hline 310 & 26.51 & 4019. & 25.10 \\
\hline 320 & 27.90 & 4291. & 25.96 \\
\hline 330 & 29.38 & 4577. & 26.84 \\
\hline 340 & 30.91 & 4877 & 27.74 \\
\hline 350 & 32.46 & 5194. & 28.66 \\
\hline 360 & 34.00 & 5526. & 29.60 \\
\hline 370 & 35.44 & 5877. & 30.55 \\
\hline 380 & 36.76 & 6248. & 31.51 \\
\hline 273.15 & 22.18 & 3125. & 22.04 \\
\hline 298.15 & 24.97 & 3714. & 24.10 \\
\hline
\end{tabular}

\section{Discussion}

The crystallinity of 45 percent for this powdery sample was estimated from heat of fusion measurements using a dynamic scanning calorimeter. Heat of fusion of a pressure crystallized linear polyethylene $(96 \%$ crystallinity) [6] was used as the reference.

Although the high molecular weight sample has lower crystallinity than the SRM 1475 in the condition as received (71\% crystallinity) [5], it shows a somewhat lower heat capacity over the temperature range 90 to $310 \mathrm{~K}$. Only at lower and higher temperatures does this sample exhibit the expected higher heat capacity. The heat capacity of this sample is very similar to that of a sample of SRM 1475 slowly cooled from the melt (88\% crystallinity) [6] in the temperature range 100 to $220 \mathrm{~K}$.

In a plot of heat capacity differences, figure 2 , between the heat capacity of this sample and that extrapolated for crystalline linear polyethylene [6], the changes in the 150 and $240 \mathrm{~K}$ regions are not as large as that for the 71 percent crystallinity sample. Beatty's data [2] are also included in figure 2. A relatively rapid heat capacity increase over that of the crystalline linear polyethylene occurs in the tempera- 
ture region of 120 to $170 \mathrm{~K}$. Above $200 \mathrm{~K}$, the scattering of the data causes difficulties in the conclusion of either the existence or nonexistence of a subtle heat capacity change. DTA or DSC studies on some other high molecular weight polyethylene samples suggested the occurrence of a step change in the heat capacity around $150 \mathrm{~K}[7,8]$ and indicated a surprisingly constant heat capacity difference between the high molecular weight sample and a high crystallinity sample [8].

The lack of a strong glass-like feature in the heat capacity behavior of this high molecular weight material is in parallel to a recent thermal expansivity study on the same materials. Low temperature thermal expansions of polyethylene samples have been studied on strips of compression molded thin films [9]. The

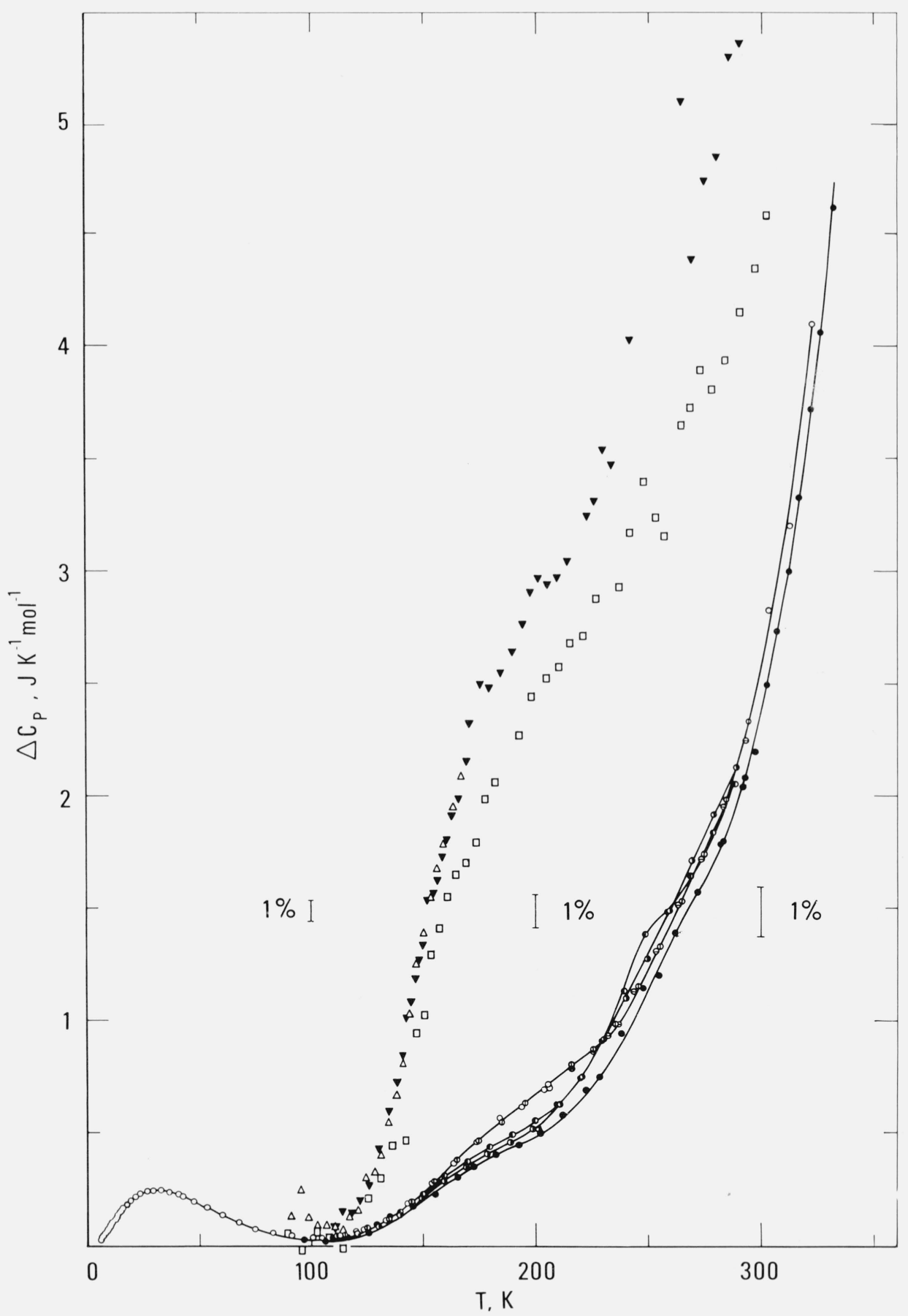

FIGURE 2. Heat capacity differences of high molecular weight linear polvethylene. 
samples included the two Standard Reference Materials 1475 and 1476 , used in a previous calorimetric study [5], and the high molecular weight sample used in the present calorimetric work. In all three samples, double peaks in the derivatives of the thermal expansion coefficients at about 110 and $150 \mathrm{~K}$ were observed. These peaks are stronger in linear polyethylene than in branched polyethylene. Weaker peaks were observed in the temperature range 180 to $200 \mathrm{~K}$. Above $200 \mathrm{~K}$, there were strong peaks in the branched polyethylene, a weak one in the high decay of the temperature of the thermometer until a thermal equilibrium is reached between the sample and the sample container assembly. The decay constant depends on the construction of the sample container, the thermal conductivity of the sample and the amount of helium gas sealed in the sample container. The decay constant is about $50 \mathrm{~s}$ for this sample container [12] at high temperatures and less at lower temperatures. Therefore up to 10 to 15 minutes may be required for the sample to reach a temperature distribution which is uniform to within $10^{-4} \mathrm{~K}$.

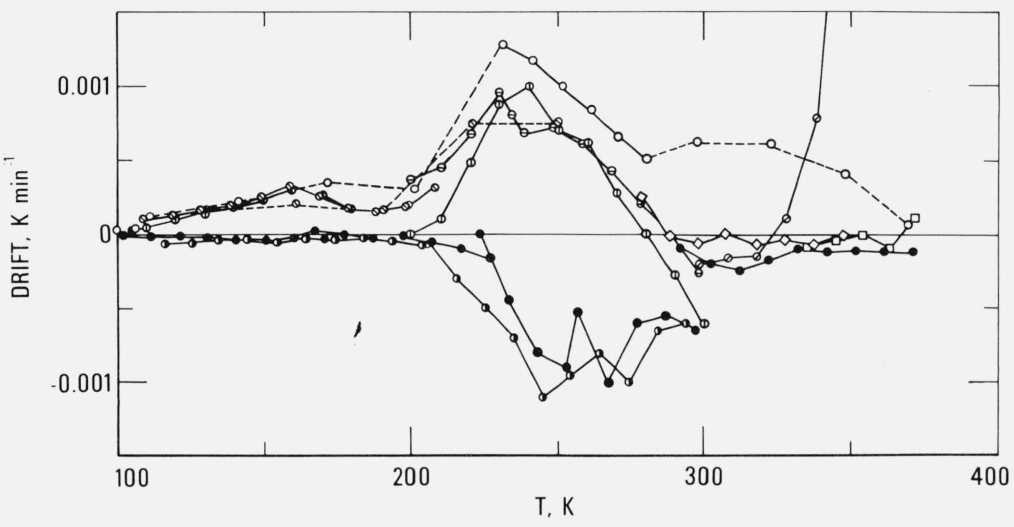

FIGURE 3. Spontaneous adiabatic temperature drift of high molecular weight linear polyethylene.

Open circles and squares (quenched): $($ S Ser. III and IV, $\ominus$ V, $\odot$ VIII, $\oslash$ XII, $\diamond$ XIII, $\square$ XIV. $\bigcirc$ before Ser. XV and $\otimes$ before Ser. IX, drift observations only. Filled or half-filled circules (annealed): I and II, XV-XVII.

molecular weight sample and only a monotonic increase in the ordinary linear polyethylene.

Although the appearance of a discontinuity in the heat capacity behavior is perhaps a necessary condition for a glass transition, it is not a sufficient condition. A broad distribution in the relaxation times may cause the glass transformation to occur over a wide temperature range, thus making a weak heat capacity discontinuity in partially crystalline material even more difficult to assess. Since the glass transition is kinetic in nature, relaxational phenomena should also be observed in the glass transition region. One highly sensitive method to detect the thermal relaxation is the method of observing the spontaneous temperature changes of the sample under adiabatic conditions [10]. The sign and the magnitude of the temperature drift as a function of time and temperature may be correlated with different thermal treatments and histories. Both the discontinuity in the heat capacity behavior and the adiabatic temperature drift are commonly observed in glass transition regions of various materials and also in glass-like transitions in crystals [11].

The drift observations are shown in figure 3 . These are the drift rates observed at 20 minutes after the heater energy has been turned off. Because of the geometric arrangement of various components in the sample container [4], the temperature of the thermometer and the heater is slightly higher than that of the sample during the heating period. Therefore, when the energy is turned off, there is an exponential
The drift behavior in the $240 \mathrm{~K}$ region for the high molecular weight material occurs in similar temperature range and magnitude as that observed for the asreceived SRM $1475[6,10]$ and is presumed to be caused by the relaxational behavior in the amorphous phase. For the quenched sample, i.e., cooling rate is greater than the rate of heat capacity determination of 5-10 K $\mathrm{h}^{-1}$, the drift rate is generally positive (exothermic) with a broad peak around $230 \mathrm{~K}$. There is also a weaker peak at around $160 \mathrm{~K}$. When the sample was heated to $370 \mathrm{~K}$ for the first time, large exothermic behavior showed up above $330 \mathrm{~K}$, indicating the onset of further crystallization processes. For the sample either slowcooled continuously to $100 \mathrm{~K}$ or annealed at 225 and $140 \mathrm{~K}$, there is an endothermic peak only around $245 \mathrm{~K}$. No endothermic behavior was observed at temperatures below $210 \mathrm{~K}$ for the sample either slow cooled or annealed. Thus the weaker exothermic peak occurring around $160 \mathrm{~K}$ for quenched samples is presumed due to some stabilization processes such as the relief of strain.

In the broad temperature region near $240 \mathrm{~K}$, the drift behavior as observed in figure 3 and in other linear polyethylene samples $[6,10]$ seems to indicate the existence of double peaks. Special thermal treatments were performed in attempts to resolve these peaks. Figure 4 shows the results of the drift observations for two combinations of quenching, annealing and slow cooling treatments. The sample was first annealed at $250 \mathrm{~K}$ for 1 day and then quenched from $250 \mathrm{~K}$. Upon 


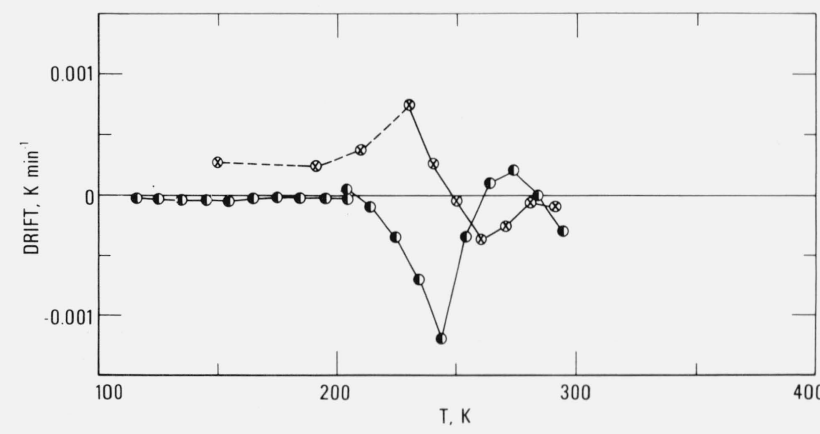

FIGURE 4. Spontaneous adiabatic temperature drift of high molecu lar weight linear polyethylene.

$\otimes$ Annealed at $250 \mathrm{~K}$ and then quenched from $250 \mathrm{~K}$ (before Ser. IX). Quenched from $360 \mathrm{~K}$ and then annealed at $225 \mathrm{~K}$ and $143 \mathrm{~K}$ (Ser. VI and VII).

heating the sample, it showed exothermic behavior, similar to that of a quenched sample, at temperatures below $250 \mathrm{~K}$. Above $250 \mathrm{~K}$, endothermic effects similar to an annealed sample were seen.

The sample was quickly cooled $\left(5 \mathrm{~K} \mathrm{~min}^{-1}\right)$ to $225 \mathrm{~K}$ and held there for 4 days, until the drift decreased from an initial value of greater than $1 \mathrm{mK} \mathrm{min}^{-1}$ to less than $0.05 \mathrm{mK} \mathrm{min}^{-1}$. It was then slowly cooled $\left(2.5 \mathrm{~K} \mathrm{~h}^{-1}\right)$ to $143 \mathrm{~K}$ and held there for 2 days. An endothermic peak was observed at about $245 \mathrm{~K}$. Above $245 \mathrm{~K}$, a small exothermic peak appeared near $270 \mathrm{~K}$. Apparently annealing at $225 \mathrm{~K}$ did not relax the configurations associated with the higher temperature peak.
The two regions around 240 and $270 \mathrm{~K}$ may be caused by different types of amorphous relaxation mechanisms, such as from the loose ends of the polymer molecules or from the molecular segments with both ends confined in crystalline regions. However, the mechanisms responsible for the relaxational behavior observed here have not been determined.

The author wishes to thank R. G. Christensen for the molecular weight determinations and C. H. Pearson for the assistance in calorimetric measurements.

\section{References}

[1] Beatty, C. L., and Karasz, F. E., Bull. Am. Phys. Soc. Ser. II, 16, 1391 (1971).

[2] Beatty, C. L., Ph. D. thesis, University of Massachusetts (1972).

[3] Dainton, F. S., Evans, D. M., Hoare, F. E., and Melia, T. P., Polymer 3,277 (1962).

[4] Sterrett, K. F., Blackburn, D. H., Bestul, A. B., Chang, S. S., and Horman, J. A., J. Res. Nat. Bur. Stand. (U.S.), 69C (Engr. and Instr.) No. 1, 19-26 (Jan.-Mar. 1965).

[5] Chang, S. S., and Bestul, A. B., J. Res. Nat. Bur. Stand. (U.S.) 77A (Phys. and Chem.), No. 4, 395-405 (July-Aug. 1973).

[6] Chang, S. S., J. Res. Nat. Bur. Stand. (U.S.), 78A (Phys. and Chem), No. 3, 387-400 (May-June 1974)

[7] Stehling, F. C., and Mandelkern, L., Macromol. 3, 242 (1969).

[8] Illers, K. H., Koll. Z 250, 426 (1972); 252, 1 (1974).

[9] Lee, S., and Simha, R., Macromol. 7,909 (1974).

[10] Chang, S. S., J. Polymer Sci. Sym. 43, 43 (1973).

[11] Suga, H., and Seki, S., J. Non-cryst. Solids 16, 171 (1974).

[12] Chang, S. S., Rev. Sci. Instr. 40, 822 (1969).

(Paper 80A1-881) 